\title{
Emotionality in two strains of mice as a function of maternal handling
}

\author{
RICHARD C. LaBARBA \\ UNIVERSITY OF SOUTH FLORIDA
}

Handling mothers in two strains of mice for 12 consecutive days resulted in reduced emotionality in the adult offspring of $B A L B / c$ mice, but not in the offspring of $C 57 B L / 6$ mice.

Increasingly more attention is being devoted to mother-infant relations in the research dealing with early experiential effects on adult patterns of behavior (Noirot, 1964a, b; Ressler, 1962; Rhinegold, 1963; Young, 1965). Denenberg et al (1962) found that shocking mother rats and/or rotating them to a litter other than their own resulted in increased emotionality in adult rat offspring. Implicit in this and similar studies which directly or indirectly manipulate ontogenetic variables is the notion that emotionality increases or decreases at least partially as a function of changes in mother-infant relations. Such changes may occur by producing physiological changes in the mother or infant, by inducing some disruption in the maternal behavior pattern, or by changing the responsiveness of the young to the mother. At any rate, the data suggest that those various treatments which result in the more obvious and dramatic disruption of motherinfant relations effect changes in adult emotionality, although we do not know the specific nature of these disruptions. Denenberg et al (1962) suggest that emotionality in rats is related to mother's emotionality, and that by increasing the level of emotionality in mothers, the infants' levels are increased. The nature of this study was such, however, as to present the strong passibility of some serious disruptions in mother-infant relationships, thereby clouding the results as to the origin of the effects.

This study represents an attempt to investigate the relationship between mother-infant emotionality without seriously or overtly disturbing mother-infant patterns such as occurs with shock, cooling, rotation, etc. It was hypothesized that handling mother mice for several minutes each day would result in decreased emotionality in the adult offspring. That is to say, that the reduction in emotional behavior (defecation, urination, timidity) which occurs as a function of handling these animals would effect changes in the mother-infant relations such that the offspring would be less emotional than controls.

Method

Two strains of mice were used: BALB/c and C57BL/ 6 , all 19th generation inbred animals, and all nulliparous females prior to breeding. The treatment and control groups consisted of three mothers to each strain and four pups to each litter, for a total $\mathrm{N}$ of 48 . All animals were raised in standard polycarbonate plastic cages with wood shavings for nesting material. Approximately $24 \mathrm{~h}$ after parturition, the mothers in the treatment group were handled for $6 \mathrm{~min}$ a day for 12 consecutive days. Handling consisted of rubbing, petting, and scratching, and permitting the animals to wander freely about the hands and forearms of the $E$. The pups were never handled during the first $\mathbf{5 0}$ days of life. Although no measures were taken of the mothers' emotionality over the course of 12 days handling, it was quite clear that their behavior changed from marked levels of defecation and urination on the first few days of handling to that of almost none over the second half of the treatment period. In addition, their exploratory behavior increased to the point where it became difficult to contain them to the hands and forearms. There is no question that the animals were almost completely fearless during this stage of handling. All animals were weaned at 21 days, and tested for emotionality in an open field at $\mathbf{5 0}$ days of age. The open field measured $3 \mathrm{ft}$ square, and was marked off in 4-in. squares. Emotionality was measured by the amount of urination, defecation, and activity during a single $3-\mathrm{min}$ trial.

Resulis

Inspection of the data revealed no differences among groups with regard to urination, latency, and squares traversed. An analysis of variance, a 2 by 2 factorial design, was computed for mean differences in number of boli. The $F$ ratios for treatment, strain, and treatment by strain were $4.78,68.05$, and 4.08 (df $=1 / 44$, $\mathrm{p}<.05, \mathrm{p}<.001$, and $\mathrm{p}<.05$, respectively). All the $\mathrm{F}$ ratios are significant. The $F$ of 68.05 for strain differences is highly significant at well beyond the .001 level. This effect is reflected in the very low index of emotionality among the C57BL/6 group. The mean number of boli for the treatment group $(N=12)$ was .33 , while that of the control group $(\mathrm{N}=12)$ was .48 . The effect of the treatment was present only in the BALB/c strain. This apparently genetic difference in emotionality in C57 mice was also obtained in an unpublished study by the author, in which these animals were found to be significantly lower in emotionality than were BALB/C and 129 strains. This strain difference accounts for the significant treatment by strain interaction. Insofar as the data assumed a $j$-curve distribution, and therefore might be construed as violating the assumptions of the analysis of variance, a Mann-Whitney $U$ test for independent samples was 
also computed. A U of 41 was obtained between groups. This value is significant at $\mathrm{p}<.05$ (one-tailed test, $\mathrm{N}_{1}=\mathrm{N}_{2}=12$ ).

These results suggest that infant emotionality in the BALB/c strain is affected by handling their mothers, and that such effects are due to subtle changes in mother-infant relations. Observations of the treatment groups revealed no noticeable departures from normal maternal behavior patterns. This study also points out the importance of using more than one strain of organism in assessing the effects of early experience on adult behavior. It is conceivable that much of the reported data concerning the effects of early experience holds true for only a particular strain or a limited number of strains, since few studies use more than a single strain of animal. Further, Ressler (1962) has reported impressive evidence that differences in maternal behavior between two species of mice is not entirely genetic in nature. Certainly the obvious task of considering and assessing these parameters with regard to their contributions to early experiential effects advises caution in the generalizations made in this area of research. We need to pay much more attention to detalled observations of mother-infant relationships. Curiously enough, almost no mention is ever made of such behavior in the now large amount of data, with a few exceptions (1.e., Young, 1965).
Lending more support to the importance of motherinfant relations, and its disruption, is the observation that if one looks at the data of Nolrot $(1964 \mathrm{a}, \mathrm{b})$, Ressler, and Rosenblatt \& Lehrman (1963) concerning the pattern of maternal behavior in mice and rats over the preweaning period, one finds some degree of overlap of peak intensities of these behaviors with the critical period hypothesis. If this overlap is meaningful, perhaps the effects are due primarily to changes in the mother-infant interaction and not to treatment variables per se.

\section{References}

DENENBERG, V. H., OTTINGER, O. R., \& STEPHENS, M. W. Effects of maternal factors upon growth and behavior of the rat. Child Develpm, 1962, 33, 65-71.

NOIROT, ELAINE, Changes in responsiveness to young in the adult mouse: the effect of external stimuli. J. comp. physiol. Psychol., 1964a, 57, 97-99.

NOIROT, ELAINE. Changes in responsiveness to young in the adult mouse: IV. Anim. Behav., 1964b, 12, 442-445.

RESSLER, R. H. Parental handling in two strains of mice reared by foster parents. Science, 1962, 137, 129-130.

RHINEGOLD, HARRIET. (Ed.) Maternal behavior in mammals New York: Wiley, 1963.

ROSENBLATT, J. S., \& LEHRMAN, D. S. In Harriet Rhinegold (Ed.), Maternal behavior in mammals. New York: Wiley, 1963. Pp. 8-57.

YOUNG, R. Influence of neonatal treatment on maternal behavior: A confounding variable. Psychon. Sci, 1965, 3, 295-296. 